\title{
Electrodialytic Removal of Cadmium from Brackish Water: Effects of Operating Parameters
}

\author{
Mourad Ben Sik Ali ${ }^{1,2, *}$, Amor Hafiane ${ }^{3}$, Mahmoud Dhahbi ${ }^{3}$ and Béchir Hamrouni ${ }^{1}$ \\ ${ }^{1}$ Desalination and Water Treatment Research Unit, Chemistry Department, Faculty of Sciences of Tunis, El \\ Manar II 2092, Tunisia \\ ${ }^{2}$ Engineering Preparatory Institute of Nabeul, University of Carthage, Merazka 8000 Nabeul, Tunisia \\ ${ }^{3}$ Water Researches and Technologies Centre of Borj-Cedria, PO Box 273, 8020 Soliman, Tunisia
}

\begin{abstract}
The continuous increase of environmental regulations make interesting to find effective and efficient methods for processing effluents containing metal ions. This research focuses on cadmium removal from brackish water by an electro-membrane process: The electrodialysis. Experiments were carried out on synthetic brackish water solutions and using a laboratory scale electrodialysis system. The influence of several parameters on process efficiency was investigated. The efficiency of this process was assessed by the determination of five parameters: The demineralization rate, the removal rate and the transport flux of cadmium, the current efficiency and the specific power consumption. The applied voltage, the feed flow rate, the $\mathrm{pH}$ and cadmium initial concentration of the feed solution have a significant effect on the process efficiency and mainly on the cadmium transfer from dilute to concentrate compartment. In contrast, feed ionic strength seems to affect only the SPC and not the R(Cd).
\end{abstract}

Keywords: Electrodialysis, Synthetic brackish water, Demineralization rate, Cadmium removal, Process efficiency.

\section{INTRODUCTION}

Cadmium is a heavy metal with an oxidation state of + II. It presents toxic effects on the kidney, the skeletal and the respiratory systems, and is classified as a human carcinogen. It is generally present in the environment at low levels. However, human activity has significantly increased those levels [1]. Cadmium concentrations in unpolluted natural waters are usually below $1 \mu \mathrm{g} \mathrm{L}^{-1}$. Contamination of drinking-water can occur as a result of the presence of cadmium as an impurity in the zinc of galvanized pipes or cadmiumcontaining solders in fittings, water heaters, water coolers and taps [2]. Levels of cadmium could be higher in areas supplied with soft water of low $\mathrm{pH}$, as this would tend to be more corrosive in plumbing systems containing cadmium. The World Health Organization considered that an amount of $3 \mu \mathrm{g} \mathrm{L}^{-1}$ of cadmium should not be exceeded for drinking water [1, 2].

The continuous increase of environmental regulations is making the development of effective and efficient methods for the treatment of the solutions containing metal ions, even at very low concentrations, interesting. A literature review indicates that there are several methods for removal of cadmium used in water purification processes. The main processes are: ion

*Address correspondence to this author at the Engineering Preparatory Institute of Nabeul, University of Carthage, Merazka, 8000, Nabeul, Tunisia; Tel: (+216) 225460 31; Fax: (+216) 72220181 ;

E-mail: mourad.bensikali@gmail.com exchange [3], adsorption [4-6] and membrane processes [7-9].

The use of membrane separation process in treating wastewater containing toxic metal ions is today an attractive and suitable technique, and it has to be easily included in whole process, which is the reason why membrane separations are being used more and more frequently. On the other hand, separation can be carried at room temperature; the modular membrane surface can be easily adjusted to the wastewater flows; and various industrial membranes are now available. In order to retain metallic ions, reverse osmosis (or at least nanofiltration) can be used due to the size of the ions in aqueous solutions. But the efficiencies of these techniques is limited by their low permeate fluxes and their high costs [7].

Electrodialysis and its associated technologies are electrochemical membrane separation processes in which ions are transferred through selective ion exchange membranes from one solution to another using an electric field as the driving force [10]. The concern in using of electrodialysis (ED) to remove inorganic contaminants such as borate, fluoride and heavy metals from water has augmented worldwide $[11,12]$. This is mainly due to that electrodialysis is a simple process and doesn't have many of the imperfections of chemical processes. The interest in this process has increased specially after the development of new membranes and new sources of energy [11]. Few studies were conducted and 
confirmed that electrodialysis is a judicious process for contaminants removing from water and wastewater.

As mentioned before, the electrodialysis is an electro membrane process especially used for the desalination of brackish water and sodium chloride recovery from sea water $[10,13]$. The transfer of ionic components from aqueous solution through ion exchange membranes is carried out under the driving force of an electrical field.

A conventional electrodialysis cell includes anion and cation exchange membranes that are alternately arranged between two electrodes (Figure 1) [14-16].

Under the effect of an electrical potential difference, the positively charged ions (cations) move to the cathode, passing through the negatively charged cation exchange membrane and retained by the positively charged anion exchange membrane. Whereas the negatively charged ions (anions) move to the anode, passing through the anion exchange membrane and stopped by the cation exchange membrane. The two types of membranes generate alternately two compartments. The overall result is an enhancement of ions in a concentrate stream (2) and a depletion of ions in a dilute stream (1) [16].

The purpose of this work is to investigate the cadmium removal efficiency from brackish water using electrodialysis. Experiments were carried out on synthetic brackish water solutions using a laboratory scale electrodialysis system. The influence of few parameters, such as applied voltage, flow rate, initial feed concentration, ionic strength and initial $\mathrm{pH}$ on process efficiency were considered. The efficiency of this process was assessed by the determination of five parameters: The demineralization rate, the compound removal rate and its transport flux, the current efficiency and the specific power consumption

\section{MATERIAL AND METHODS}

\subsection{Electrodialysis Equipment and Membranes}

Electrodialyzer supplied by PCA-Polymerchemie Altmeier $\mathrm{GmbH}$ and $\mathrm{PCC}$ ll $\mathrm{GmbH}$, Heusweiler (Germany) was used in this study. It consists of: an ED cell, three tanks for respectively the dilute, the concentrate and the electrodes rinse solutions, a power direct current generator and three centrifugal pumps. A simplified diagram of the electrodialysis setup working in continuous mode is shown in the Figure 2.

The stack configuration of the ED cell is shown in Figure 3. It comprised three standard cation-exchange membranes (PCA-SK) and two standard anionexchange membranes (PCA-SA). These membranes were also supplied by PCCell $\mathrm{GmbH}$, Heusweiler

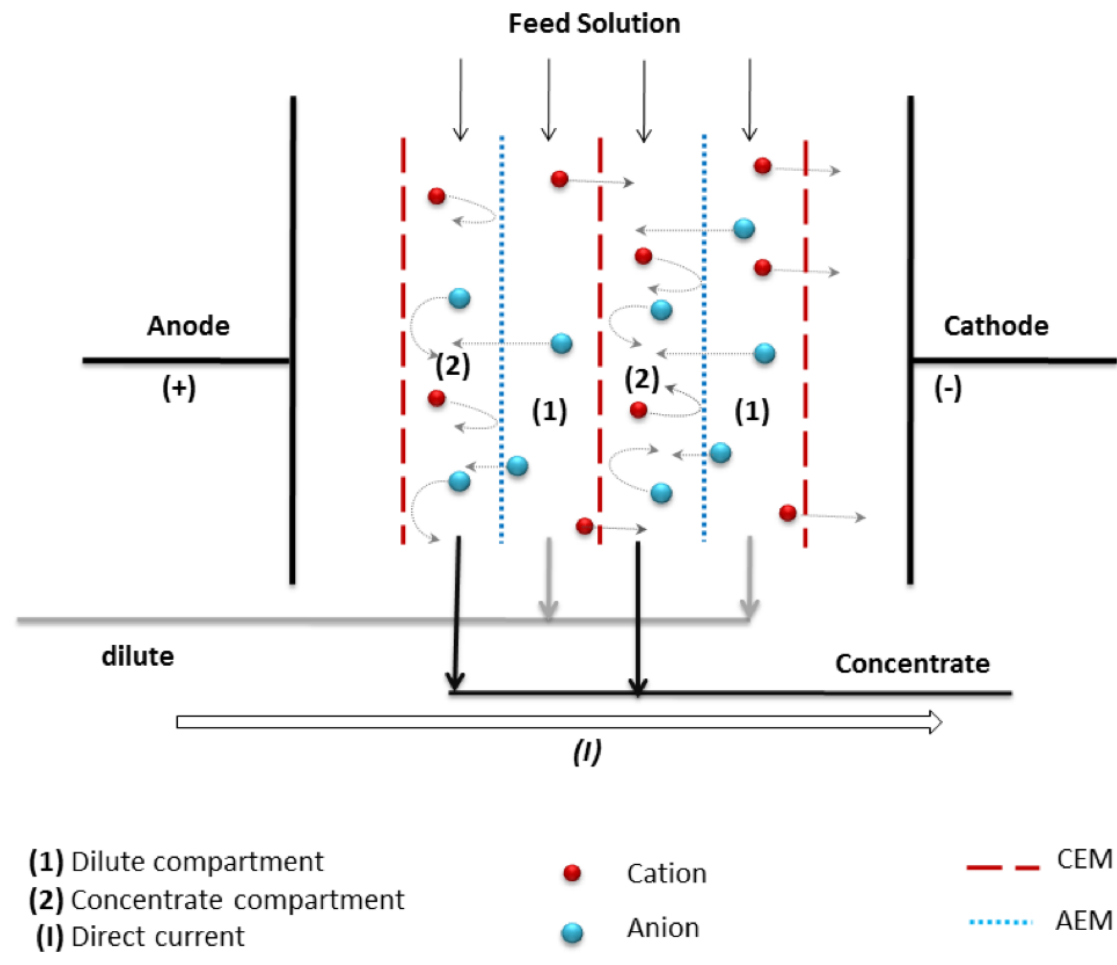

Figure 1: Principle of electrodialysis. 


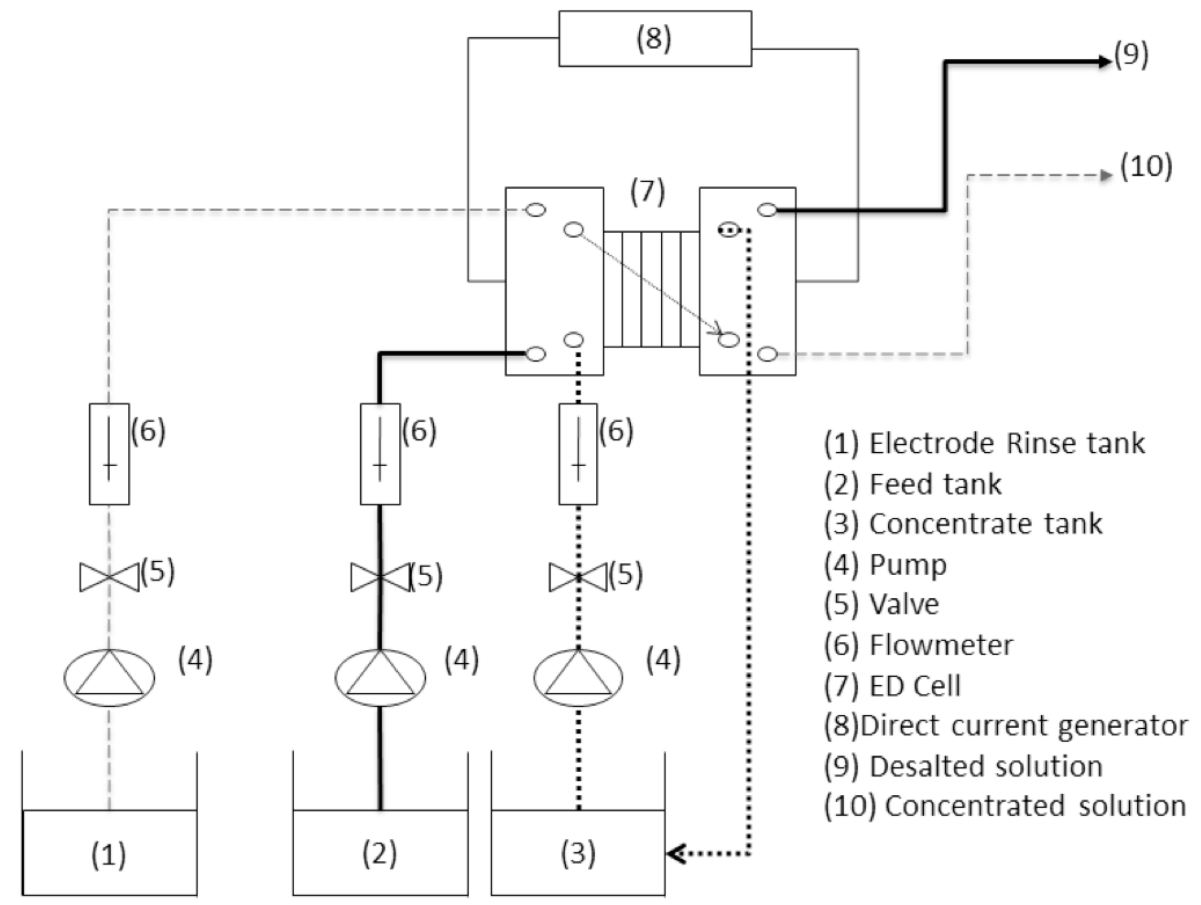

Figure 2: Schematic of the electrodialysis system used in this study.

Table 1: Main PCA-SK and PCA-SA Properties

\begin{tabular}{|c|c|c|c|c|c|c|}
\hline Membrane & $\begin{array}{c}\text { Thickness } \\
(\boldsymbol{\mu m})\end{array}$ & $\begin{array}{c}\text { lon Exchange } \\
\text { cCapacity } \\
\left(\mathbf{m e q ~ g}^{-1}\right)\end{array}$ & $\begin{array}{c}\text { Chemical } \\
\text { Stability }(\mathbf{p H})\end{array}$ & $\begin{array}{c}\text { Perm } \\
\text { selectivity }\end{array}$ & $\begin{array}{c}\text { Functional } \\
\text { Groups }\end{array}$ & $\begin{array}{c}\text { Membrane } \\
\text { Resistance }\left(\boldsymbol{\Omega} \mathbf{c m}^{2}\right)\end{array}$ \\
\hline \hline PCA-SK & 130 & $\sim 1$ & $0-11$ & $>0.93$ & $-\mathrm{SO}_{3}^{-}$ & $0.75-3$ \\
\hline PCA-SA & $90-130$ & $\sim 1.5$ & $0-9$ & $>0.96$ & $-\mathrm{NR}_{4}^{-}$ & $1-1.5$ \\
\hline
\end{tabular}

(Germany). There specific properties are presented in Table 1.

The effective area of each membrane was $64 \mathrm{~cm}^{2}$. Plastic separators (spacers) are placed between them to form the flow paths of the different compartments. This arrangement defined three independent compartments (dilute stream, concentrate stream and electrode stream). The flow channel width between two membranes is $0.5 \mathrm{~mm}$. As shown in Figure 3, membranes and spacers were arranged between two electrodes made of $\mathrm{Pt} / \mathrm{lr}$ - coated Titanium.

Solutions were continuously pumped through each compartment from reservoir tanks using adjustable pumps.

\subsection{Reagents}

Analytical grade salts (sodium chloride, cadmium chloride dehydrates and sodium sulphate) and distilled water were used in all experiments to prepare the synthetic brackish water solutions and the electrode rinse solution. All reagents were supplied by SigmaAldrich Chemie GmbH (Switzerland).

\subsection{Experimental Procedure}

During an ED process, a harmful gazes (chlorine ...) or sub-products (hypochlorite ...) can be produced at electrodes surfaces. For this reason and to protect the membranes and mainly the electrodes, an electrodes rinse solution with a relatively high velocity $\left(80 \mathrm{~L} \mathrm{~h}^{-1}\right)$ and salinity $\left(0.1 \mathrm{M} \mathrm{Na}_{2} \mathrm{SO}_{4}\right)$ was circulated inside the electrodes compartments.

Before each experiment, a synthetic brackish water solution is prepared by dissolving salts in distilled water. The ionic strength was then fixed by adjusting the concentration of sodium chloride. Finally, $\mathrm{pH}$ was corrected by $\mathrm{HCl}(0.1 \mathrm{M})$ or $\mathrm{NaOH}(0.1 \mathrm{M})$,

As initial concentrate and dilute, the same prepared solution was used. Their flow rates (dilute and 


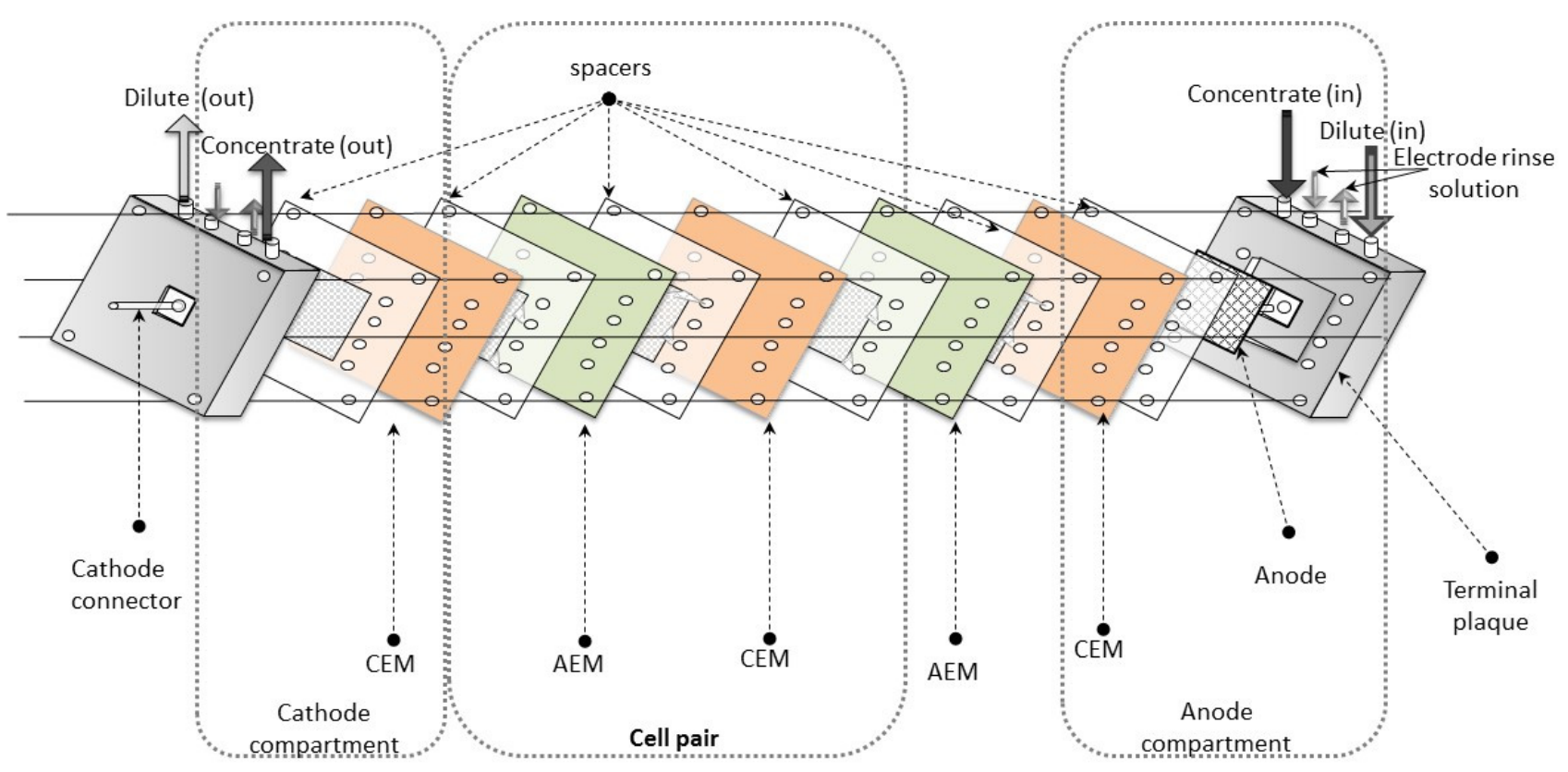

Figure 3: Schematic of the ED cell used in this study.

concentrate) were adjusted at the beginning of experiment. The ED process starts by applying a potential difference (applied voltage) between electrodes using the direct current generator. Samples from each compartment were collected at the inlet (before treatment) and outlet (after treatment).

At the end of each assay, the system was cleaned by circulating successively solutions of $0.1 \mathrm{M} \mathrm{HCl}, 0.1$ $\mathrm{M} \mathrm{NaOH}$ and distilled water through the ED cell during 30 min each.

\subsection{Analytical Methods}

Conductivity and temperature of samples were measured online using a conductivity meter ((712 Conductometer, Metrohm AG, Switzerland).

Cadmium amounts were determined by atomic absorption spectrometer (AAS Vario 6 spectrometer, Germany). All samples were acidified before analysis.

Solutions $\mathrm{pH}$ were quantified by a $\mathrm{pH}$-meter (654 $\mathrm{pH}$-meter, Metrohm AG, Switzerland) equipped with a glass electrode.

\subsection{Data Analysis}

The purpose of this work was to investigate the effects of few parameters on electrodialysis cell performance for cadmium removal. The efficiency of this process can be assessed by the determination of five parameters: The demineralization rate, the compound removal rate and its transport flux, the current efficiency and the specific power consumption.

All figures and tables refer to changes in the dilute. The mass balance of the ions initially existing in the feed solution was verified for dilute, concentrate and electrode rinse solution. Therefore, data for concentrate and electrode rinse solution will not be presented in this paper.

\subsubsection{Demineralization Rate $D R$}

The conductivity allowed following the total amount of salts removed: the demineralization rate (DR) which can be calculated as $[17,18]$ :

$$
D R(\%)=100 \cdot\left(1-\frac{C_{t}}{C_{0}}\right)
$$

Where DR is the demineralization rate expressed in percentage, $C_{0}$ and $C_{t}$ are, respectively, the conductivity of the solution before and after treatment (expressed in $\mathrm{mS} \mathrm{cm}^{-1}$ ).

\subsubsection{Removal Rate of Cadmium R (Cd)}

To discuss the metal removal and then process efficiency, the removal percentage was evaluated for all experiments. The amount of cadmium removed was defined as:

$$
R(C d)(\%)=100 .\left(1-\frac{[C d]_{t}}{[C d]_{0}}\right)
$$


Where $[C d]_{t}$ and $[C d]_{0}$ were respectively the cadmium concentration $\left(\mathrm{mol} \mathrm{L}^{-1}\right)$ in the dilute compartment and in the feed solution.

\subsubsection{The Cadmium Transport Flux J(Cd)}

Kinetic of cadmium transport from the feed (dilute compartment) to the receiver phase (concentrate compartment) can also be evaluated by the ionic flux (J). It was determined using the following equation [19]:

$$
J\left(m o l \mathrm{~cm}^{-2} \mathrm{~s}^{-1}\right)=\left(\frac{V}{A}\right)\left(\frac{\Delta C}{T}\right)
$$

Where $V(L)$ is the volume of the concentrate compartment (receiver phase), A $\left(\mathrm{cm}^{2}\right)$ is the effective membrane area, $\Delta C\left(\mathrm{~mol} \mathrm{~L}^{-1}\right)$ is the transported amount of cadmium at a period time $\mathrm{T}$ (s).

\subsubsection{Specific Power Consumption SPC}

The energy required to treat a unit volume of solution is called the Specific power consumption (SPC). It can be calculated using the following equation [19]:

$$
S P C\left(W h L^{-1}\right)=\frac{E \cdot \int_{0}^{t} I(t) d t}{V}
$$

Where $E(V)$ is the applied potential, I (A) the applied current, $V(L)$ the dilute stream volume and $t(h)$ is the time.

\subsubsection{The Current Efficiency CE}

The amount of ion crossing the membrane from the feed (dilute) to the receiver (concentrate) solutions during an interval of time $\Delta t$ can be compared to the real number of faradays consumed in the operation. The ratio of these two quantities is called current efficiency (CE).

The current efficiency is an important parameter that defines the applicability of the electrodialysis process. It can indicate how effective ions are transported across the membranes for a given applied current. CE can be calculated using the following equation $[20,21]$ :

$$
C E=\frac{\Delta N_{A} \cdot F}{Q}
$$

Where $\Delta N_{A}(N)$ is the equivalent number of an ion $A$ transferred per cell during the interval of time $\Delta t(\mathrm{~s}), \mathrm{Q}$ the current quantity supplied to the system during the same time and $\mathrm{F}$ is the Faraday constant (96 $485 \mathrm{~A} \mathrm{~s}$ $\left.\mathrm{mol}^{-1}\right)$.

\section{RESULTS AND DISCUSSION}

\subsection{Effects of Applied Voltage}

To study the effect of applied voltage, the ionic strength, $\mathrm{pH}$, cadmium concentration of feed solution and the inlet velocity were fixed respectively to 0.025 $\mathrm{M}, 5,6 \mathrm{mg} \mathrm{L}^{-1}$ and $17 \mathrm{~L} \mathrm{~h}^{-1}$.

The influences of applied voltages on the DR, R (Cd), J (Cd), CE and SPC are shown in Figure 4.

Figure 4a shows that the demineralization rate increases by increasing the applied voltage. In this graph, three zones are distinguished. For low applied voltage $(E<2 \mathrm{~V})$ the demineralization increases slightly by increasing voltage drop. Previous work [13] showed that in these experimental conditions the resistance of the stack is relatively high. The applied voltage is not so significant to overcome the resistance of membranes and then not able to transport ions. As consequence there are few transports of ions from the dilute to the concentrate compartments. This is also confirmed in Figure 4b where low ionic fluxes are obtained in this region.

For higher applied voltage $(2 \mathrm{~V}<\mathrm{E}<12 \mathrm{~V})$, the transport of ions between the different cell compartments is proportional to current. As shown in Figures $\mathbf{4 a}$ and $\mathbf{4 b}$, there is a more or less linear increase of the demineralization rate and ionic flux.

In the last part $(E>12 \mathrm{~V})$, the increase of the applied voltage does not conduct to an important increase in the demineralization rate and ionic flux. At this point the limiting current density is reached. No significant increase is observed in the current density and transport from the dilute to the concentrate compartment with increasing applied voltage.

Figure 4a also shows that the curve corresponding to cadmium removal have also similar behavior. The three notable regions are visibly distinguished. Cadmium ions are transported in the same way as other ions. As conclusion, there is no effect of applied voltage on the selectivity of ionic transport. Other metal ions don't present the same behavior. In fact, a previous work [22], showed that iron is removed proportionally to applied voltage even if this last is too low. Apparently ferric ions transport is preferred than those of other coexisting ions. 


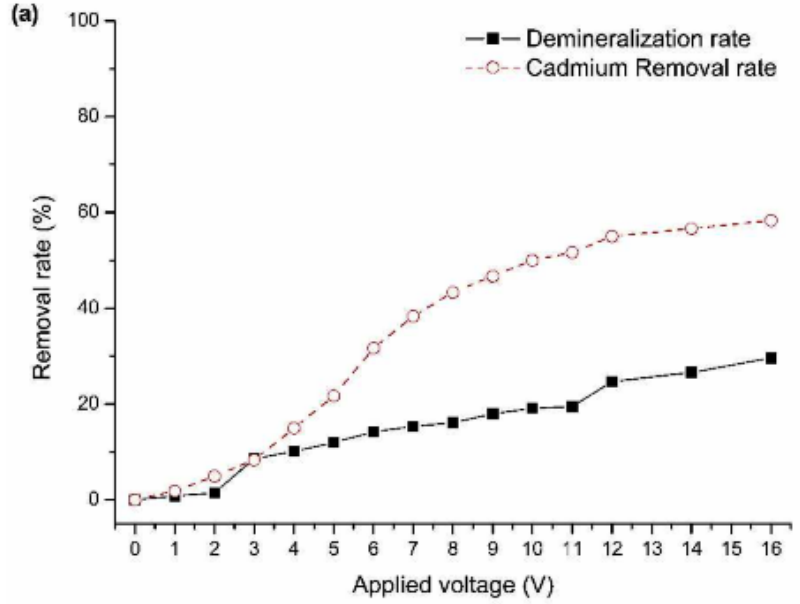

(c)

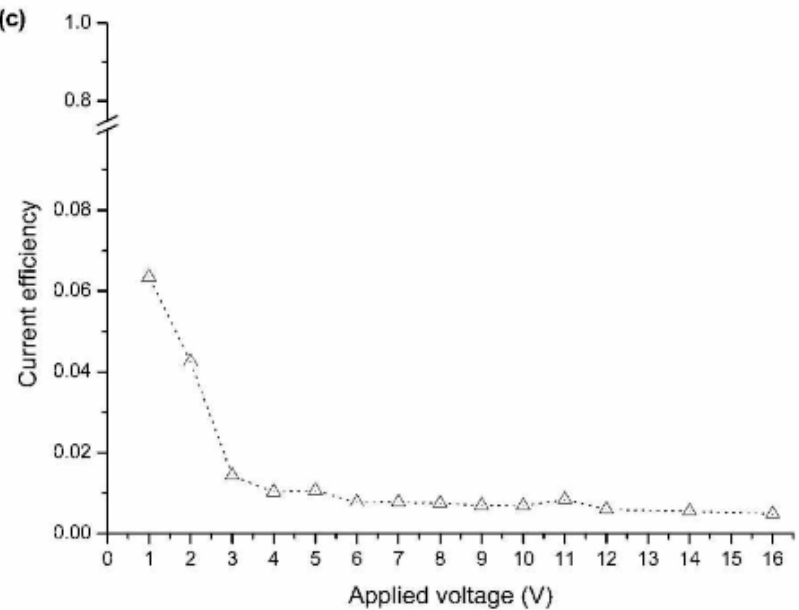

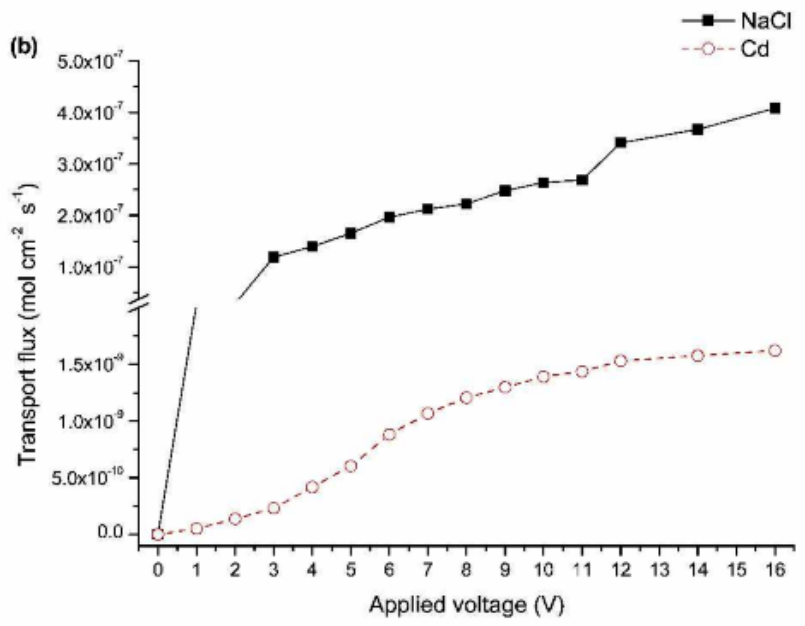

(d)

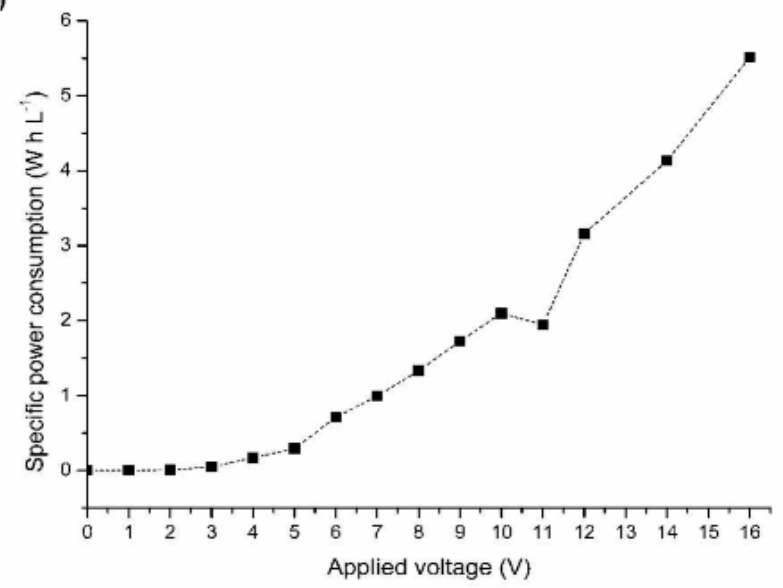

Figure 4: Effect of applied voltage on the demineralization and cadmium removal rate (a), cadmium transport (b), current efficiency (c) and specific power consumption (d) (cadmium initial feed concentration $6 \mathrm{mg} \mathrm{L}^{-1}$; ionic strength $0.025 \mathrm{M}^{-} \mathrm{pH} 5$, feed flow rate $17 \mathrm{~L} \mathrm{~h}^{-1}$ ).

As presented in Figure 4c, the current efficiency decreases by increasing the applied voltage. The induced current is not only used to cadmium ions transport but also to transport coexisting ions and to split water. Same results were obtained in previous work [22, 23].

As shown in Figure 4d, the specific power consumption increases by increasing the applied voltage. This is expected because the SPC depends on the applied voltage and current.

$\mathrm{R}(\mathrm{Cd})$ and $\mathrm{J}(\mathrm{Cd})$ were almost constant when the applied voltage surpass $10 \mathrm{~V}$. Their limits are obtained at this voltage. In these conditions a clear variation of $\mathrm{pH}$ of dilute solution is observed. The chemical forms of cadmium in solution perhaps play a key role on the cadmium retaining. At this region, the current efficiency remained relatively low but the specific power consumption has increased proportionally to applied voltage.

\subsection{Effects of Flow Rate}

The ionic strength, cadmium concentration and $\mathrm{pH}$ of feed solution were adjusted respectively to $0.025 \mathrm{M}$, $6 \mathrm{mg} \mathrm{L}^{-1}$ and 5 . The flow rate of dilute compartment was varied from 10 to $28 \mathrm{~L} \mathrm{~h}^{-1}$.

It was not possible to increase the flow rate above $28 \mathrm{~L} \mathrm{~h}^{-1}$ since the extreme capacity of the pumps in the present system is defined as $28 \mathrm{~L} \mathrm{~h}^{-1}$.

Experiments were performed by applying 2, 5 and 8 $V$ each time across the entire assembly. The impacts of the flow rate on the ED performances are illustrated in Figure 5.

As seen in Figure 5, flow rate has a significant effect on cadmium removal in the range studied. In Figure 5a we notice that cadmium removal declines with an increase of the flow rate. This can be explicated by the remaining time of ions inside the different 
(a)

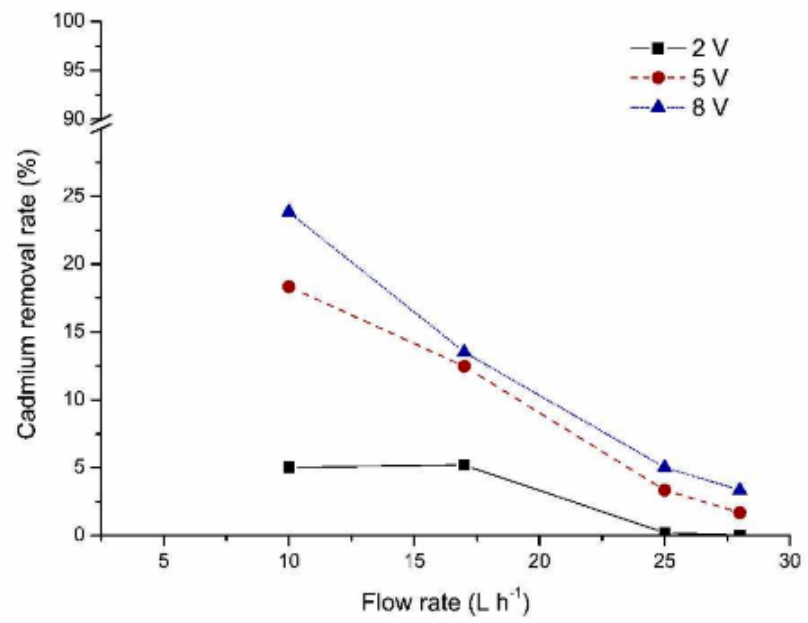

(c)

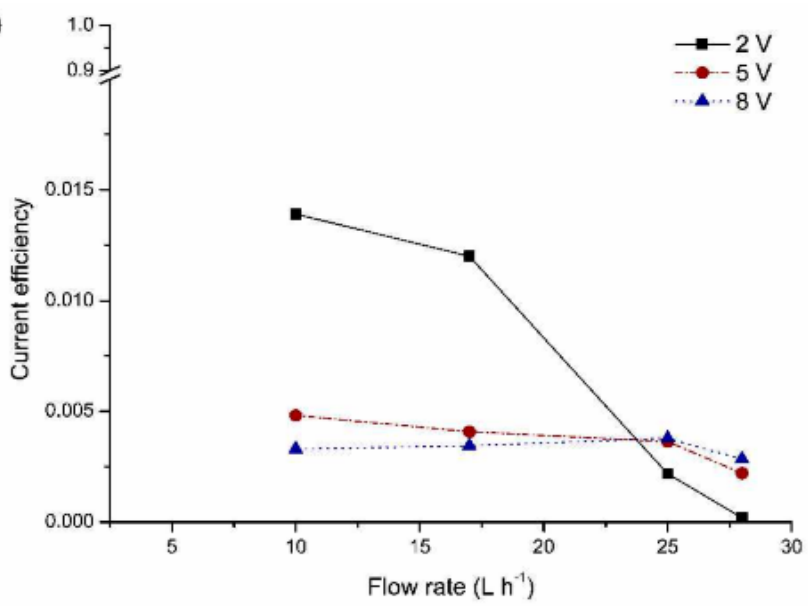

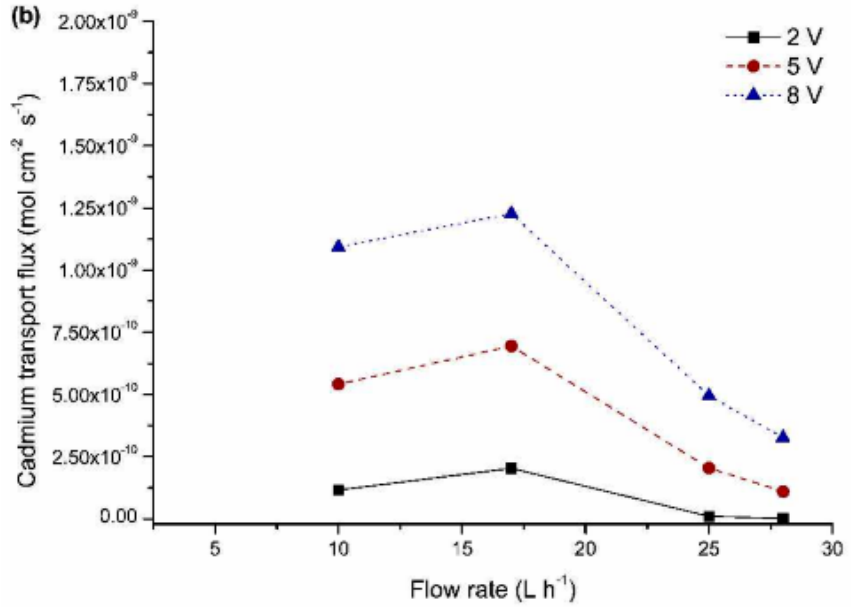

(d)

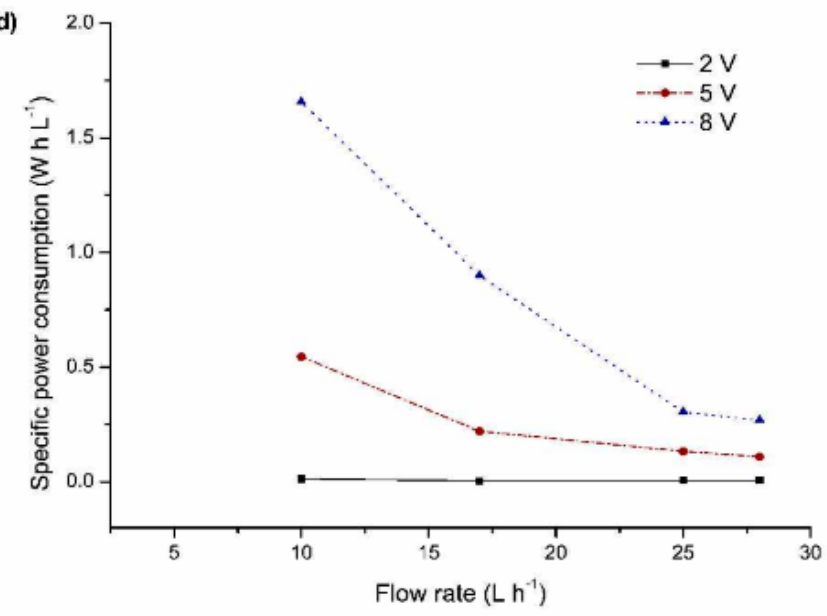

Figure 5: Effect of flow rate on (a) the cadmium removal, (b) cadmium transport, (c) current efficiency and (d) specific power consumption (ionic strength $0.025 \mathrm{M}$; cadmium concentration $6 \mathrm{mg} \mathrm{L}^{-1} ; \mathrm{pH}$ ).

compartments of the cell. In fact the ions have more time to be transported from one compartment to another thought the membrane when the velocity or flow rate is lower. This can lead to an increase of the total amount of salts transported and so to an increase of separation percentage $[13,22,23]$.

Previous study [13] showed that ionic flux transport of salts decreases by increasing feed flow rates. This is also the case of cadmium. In fact, Figure $\mathbf{5 b}$ shows that more cadmium transport from dilute to concentrate compartments is achieved at low flow rates.

In other hand and as showed in Figure 5c the current efficiency declines when the flow rate increases. This endorses the obtained results. Effectively more current is used to transport cadmium species at low flow rate.

As illustrated in Figure $\mathbf{5 d}$ the specific power consumption depends also on this parameter. SPC is higher for low flow rate. For that, medium flow rates are suggested to get better separation and power consumption.

\subsection{Effects of Initial pH}

The removal of cadmium was studied at different $\mathrm{pH}$ values ranging from 2 to 12 and a fixed initial cadmium solution of $6 \mathrm{mg} \mathrm{L}^{-1}$. Effects of $\mathrm{pH}$ of the feed solution on the removal and transport of cadmium are illustrated in Figure 6.

As shown in Figure 6, a clear dependency between the cadmium transport (and removal rate) and the $\mathrm{pH}$ of a solution is observed. So, in a $\mathrm{pH}$ range of 2 to $\sim 7$, the cadmium transport (or removal) is almost constant, and it lowers sharply when $\mathrm{pH}$ exceeds 7 .

It was supposed that these results were due to the nature of cadmium in aqueous solutions [9]. Mainly, they were due to the presence of charged or not charged cadmium species in the solution. 

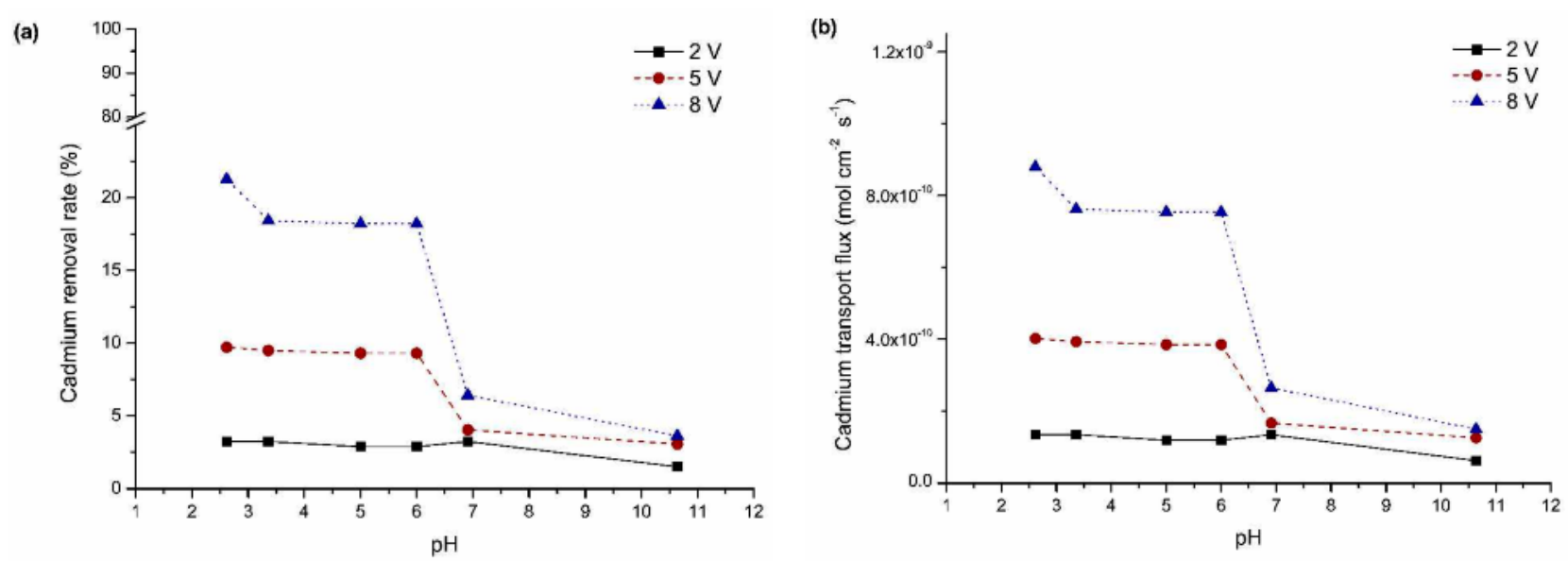

Figure 6: Effect of the $\mathrm{pH}$ of the feed solution on (a) the removal and (b) transport of cadmium (feed flow rate $17 \mathrm{~L} \mathrm{~h}^{-1}$; ionic strength $0.025 \mathrm{M}$; cadmium concentration $6 \mathrm{mg} \mathrm{L}^{-1}$ ).

The shape of the curves established approximately coincides with that of the repartition of charged cadmium species vs. $\mathrm{pH}$.

The speciation diagram presented in Figure 6 has been gotten with the Medusa software, a freely available software for the creation of speciation diagrams, and is valid for a $0.05 \mathrm{mM} \mathrm{Cd}(\mathrm{II})$ solution at variable $\mathrm{pH}$ [24].

This diagram indicates that soluble cadmium charged ions exists for solutions with $\mathrm{pH}$ under 7 . In this range of $\mathrm{pH} \mathrm{Cd}(\mathrm{II})$ ions can be transported through membranes under the effect of applied current. As consequence, the cadmium removal rates were maxima.

After $\mathrm{pH}=7$, cadmium hydroxides charged complexes appears. The transports of these species are reduced and removal rate of cadmium is consequently reduced.

The cadmium speciation diagram shows also that only non-charged cadmium hydroxide form can exist after $\mathrm{pH}=9$. This composite cannot be transported by electrodialysis process. For that reason the cadmium removal were low.

Also, at high $\mathrm{pH}$ (more than $\mathrm{pH} 7$ ) some scaling problems can appear. An accumulation of cadmium hydroxides, in the neighborhood of the membrane, caused by concentration polarization and deposit layer formation, can be expected.

An interaction (adsorption) with the membrane material can occur thus a layer of these species on the membrane will be formed. These phenomena have a great effect on the electrodialysis performance. It

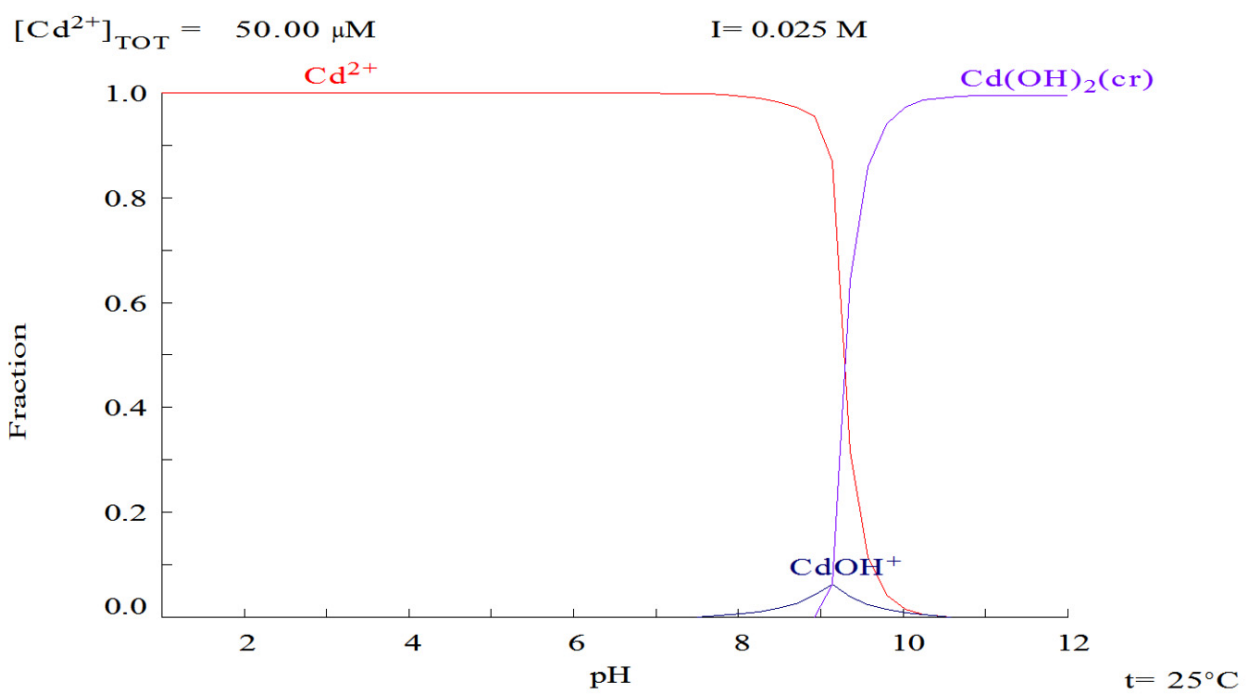

Figure 7: Chemical speciation diagram of a $0.05 \mathrm{mM} \mathrm{Cd(II)} \mathrm{solution.}$ 
(a)

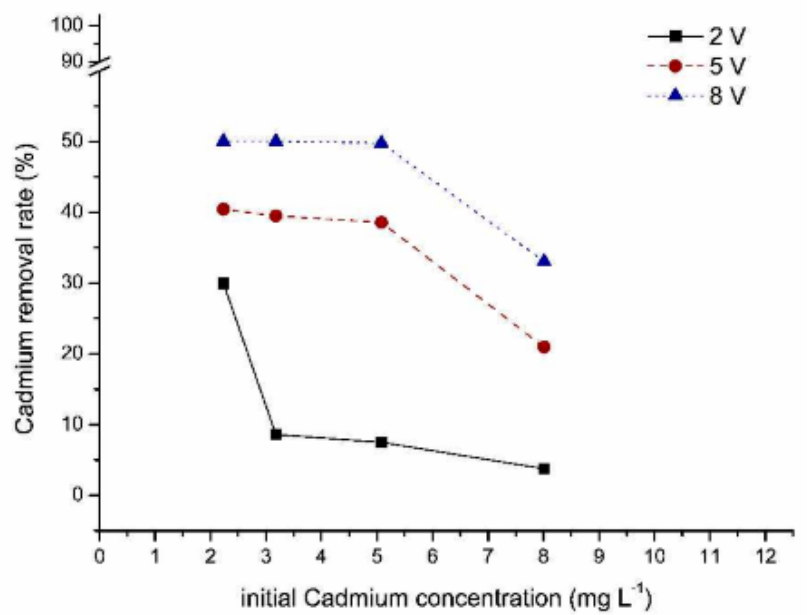

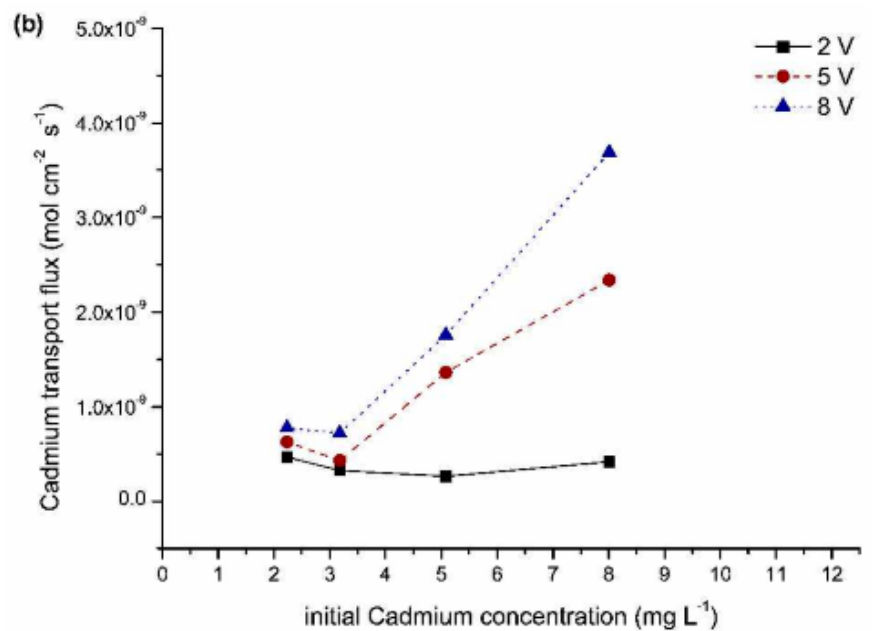

Figure 8: Effect of initial cadmium concentration on (a) the cadmium removal and (b) cadmium flux (feed flow rate $18 \mathrm{~L} \mathrm{~h}^{-1} ; \mathrm{pH}$ 3; ionic strength $0.025 \mathrm{M}$ ).

diminishes the process efficiency and increases the power consumption.

\subsection{Effects of Cadmium Initial Concentration}

The effect of initial feed concentration on cadmium removal performance from aqueous solution was investigated using aqueous solutions with various concentrations of cadmium.

The ionic strength, the $\mathrm{pH}$ and the flow rate of feed solution were initially fixed respectively to $0.025 \mathrm{M}, 5$ and $18 \mathrm{~L} \mathrm{~h}^{-1}$. Three voltage $(2,5$ and $8 \mathrm{~V})$ was respectively applied across the entire assembly for each experiment.

As shown in Figure 8a the cadmium removal has a significant dependency on the feed solution in this range of concentration.

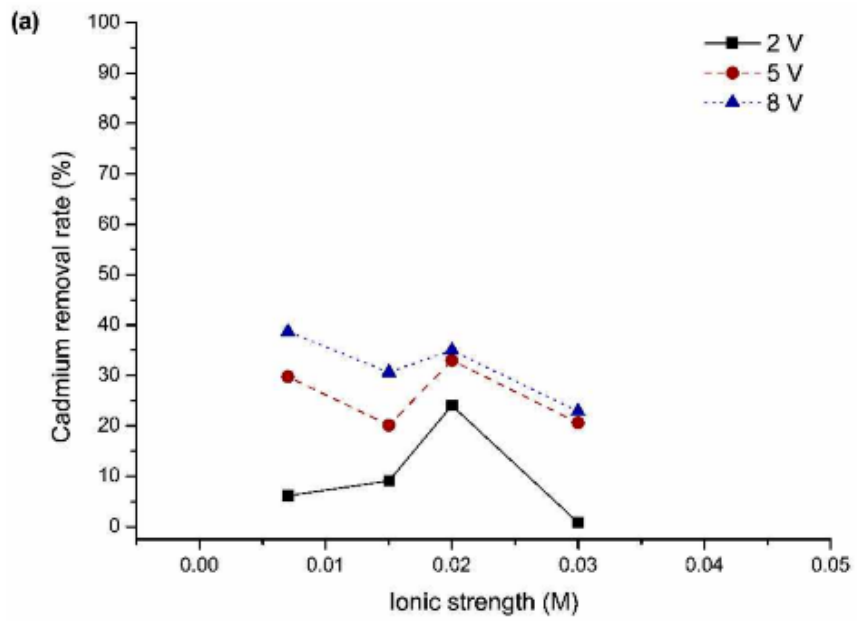

The maximum cadmium removal is found for lower initial concentration (under $5 \mathrm{mg} \mathrm{L}^{-1}$ in this case). An increase of the initial concentration leads to the decrease of the cadmium removal. In fact at similar hydrodynamic and electrical conditions, the number of ions transferred through the membranes is almost the same but total amounts of cadmium are quite different from the diverse treated solution. As known the calculation of removal rate depends strongly on the initial feed concentrations and the amount of transported ions. So the cadmium removal changes reciprocally to the initial feed concentration at same hydrodynamic and electrical conditions.

The cadmium initial concentration doesn't have an effect on the current efficiency and specific power consumption.

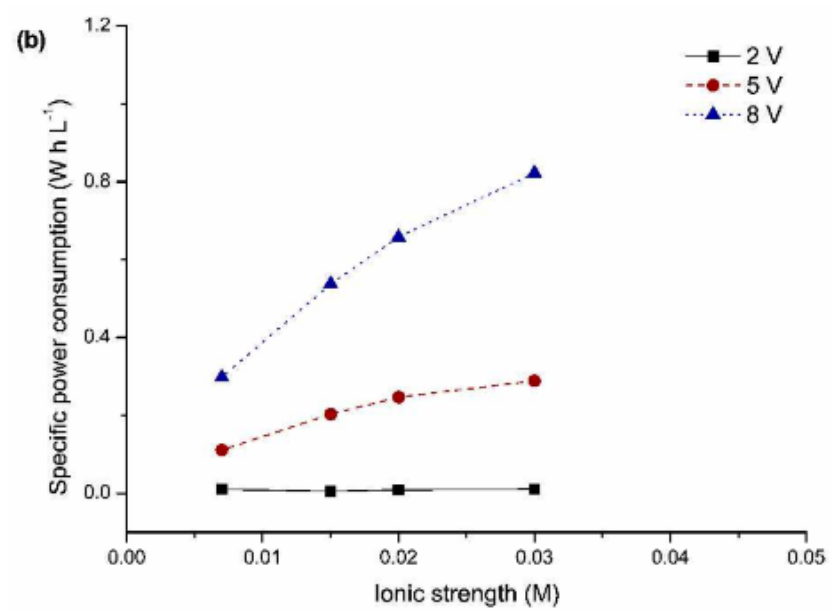

Figure 9: Effect of the ionic strength of feed solution on (a) the cadmium removal and (b) specific power consumption (feed flow rate $17 \mathrm{~L} \mathrm{~h}^{-1}$; $\mathrm{pH} 5$; cadmium concentration $6 \mathrm{mg} \mathrm{L}^{-1}$ ). 


\subsection{Effects of lonic Strength}

The effect of the feed solution ionic strength on the removal of cadmium was studied using aqueous solutions at various concentrations of $\mathrm{NaCl}$ salt. The ionic strength of feed solution was varied from $710^{-3} \mathrm{M}$ to $310^{-2} \mathrm{M}$. The $\mathrm{pH}$ and cadmium concentration of prepared solution were fixed respectively to 5 and $6 \mathrm{mg}$ $\mathrm{L}^{-1}$. The flow rate of dilute and concentrate were adjusted to $17 \mathrm{~L} \mathrm{~h}^{-1}$. 2, 5 and $8 \mathrm{~V}$ was respectively applied across the entire assembly. Figure 8 represent the effects of the ionic strength of feed solution on electrodialysis performances.

As shown in Figure 9a, the initial salt concentration didn't have a important effect on the cadmium removal. But, the effect is visibly noted on the specific power consumption. The specific power consumption is closely depending on ionic strength as seen in Figure $9 \mathrm{~b}$. The increase of salts concentration in the solution leads to an increase of the conductivity of solution. As consequence the electric current induced and then the specific power consumption are greater.

\section{CONCLUSIONS}

This study showed that the removal of cadmium which is classified as one of the most toxic heavy metals from brackish water by electrodialysis is depending on several parameters:

Until $10 \mathrm{~V}$, better results were obtained for higher applied voltage.

- Efficiency of cadmium removal declines by increasing the feed flow rate. Although, the power consumption is higher for lower flow rate.

A strong relationship between cadmium removal and the $\mathrm{pH}$ of treated solution is deduced. It was thought that this probably due to the presence of charged or not charged cadmium spices in the solution. So, in a $\mathrm{pH}$ range of 2 to 7 , cadmium transport (or removal) is almost constant. But it lowers sharply when $\mathrm{pH}$ exceeds 7 .

Maximum cadmium removal is obtained for lower initial concentration (under $5 \mathrm{mg} \mathrm{L}^{-1}$ in this case). An increase of the initial concentration conducts to the decrease of the cadmium removal. Although, this parameter doesn't have an effect on energetic performances.

The initial salt concentration or ionic strength seems to not have an important effect on process efficiency. But, the effect is clearly noted on the specific power consumption.

\section{REFERENCES}

[1] World Health Organization. Cadmium in Drinking-water; 2011: Available from: http://www.who.int/water_sanitation_ health/dwq/chemicals/cadmium.pdf

[2] World Health Organization. Guidelines for drinking-water quality.4th ed.; 2011: Available from: http://whqlibdoc.who.int/ publications/2011/9789241548151_eng.pdf

[3] Naushad M, Al-Othman ZA, Islam M. Adsorption of cadmium ion using a new composite cation-exchanger polyaniline $\mathrm{Sn}(\mathrm{IV})$ silicate: kinetics, thermodynamic and isotherm studies. Int J Environ Sci Technol 2013; 10: 567-78. http://dx.doi.org/10.1007/s13762-013-0189-0

[4] Abdel Salam M. Removal of heavy metal ions from aqueous solutions with multi-walled carbon nanotubes: Kinetic and thermodynamic studies. Int J Environ Sci Technol 2012: 112.

[5] Kumar R, Jain SK, Misra RK, Kachchwaha M, Khatri PK. Aqueous heavy metals removal by adsorption on $\beta$-diketonefunctionalized styrene-divinylbenzene copolymeric resin. Int J Environ Sci Technol 2012; 9: 79-84. http://dx.doi.org/10.1007/s13762-011-0019-1

[6] Zamani AA, Shokri R, Yaftian MR, Parizanganeh AH. Adsorption of lead, zinc and cadmium ions from contaminated water onto Peganum harmala seeds as biosorbent. Int J Environ Sci Technol 2013; 10: 93-102. http://dx.doi.org/10.1007/s13762-012-0107-x

[7] Ballet GT, Gzara L, Hafiane A, Dhahbi M. Transport coefficients and cadmium salt rejection in nanofiltration membrane. Desalination 2004; 167: 369-76. http://dx.doi.org/10.1016/j.desal.2004.06.148

[8] Jellouli Ennigrou D, Gzara L, Ramzi Ben Romdhane M, Dhahbi M. Cadmium removal from aqueous solutions by polyelectrolyte enhanced ultrafiltration. Desalination 2009; 246: 363-9.

http://dx.doi.org/10.1016/j.desal.2008.04.053

[9] Lee G. Effects of operating parameters on the removal performance of electrodialysis for treating wastewater containing cadmium. Desalin Water Treat 2011; 35: 150-7. http://dx.doi.org/10.5004/dwt.2011.2850

[10] Ghyselbrecht K, Huygebaert M, Van der Bruggen B, Ballet R, Meesschaert B, Pinoy L. Desalination of an industrial saline water with conventional and bipolar membrane electrodialysis. Desalination 2013; 318: 9-18. http://dx.doi.org/10.1016/j.desal.2013.03.020

[11] Banasiak LJ, Schäfer AI. Removal of boron, fluoride and nitrate by electrodialysis in the presence of organic matter. $J$ Memb Sci 2009; 334: 101-9.

http://dx.doi.org/10.1016/j.memsci.2009.02.020

[12] Moon SH, Yun SH. Process integration of electrodialysis for a cleaner environment. Curr Opin Chem Eng 2014; 4: 25-31. http://dx.doi.org/10.1016/j.coche.2014.01.001

[13] Ben Sik Ali M, Mnif A, Hamrouni B, Dhahbi M. Electrodialytic desalination of brackish water: Effect of process parameters and water characteristics. Ionics 2010; 16: 621-9. http://dx.doi.org/10.1007/s11581-010-0441-2

[14] Baker RW. Membrane technology and applications. $2^{\text {nd }}$ ed. John Wiley \& Sons: England 2004. http://dx.doi.org/10.1002/0470020393

[15] Noble RD, Stern SA. Membrane separations technologies Principles and Applications.Elsevier Science: Amsterdam 1995.

[16] Strathmann H. Electrodialysis, a mature technology with a multitude of new applications. Desalination 2010; 264: 26888.

http://dx.doi.org/10.1016/j.desal.2010.04.069 
[17] Casademont C, Farias MA, Pourcelly G, Bazinet L. Impact of electrodialytic parameters on cation migration kinetics and fouling nature of ion-exchange membranes during treatment of solutions with different magnesium/calcium ratios. J Memb Sci 2008; 325: 570-9. http://dx.doi.org/10.1016/j.memsci.2008.08.023

[18] Wang $Q$, Ying T, Jiang T, Yang D, Jahangir MM. Demineralization of soybean oligosaccharides extract from sweet slurry by conventional electrodialysis. J Food Eng 2009; 95: 410-5. http://dx.doi.org/10.1016/j.jfoodeng.2009.05.024

[19] Ergun E, Tor A, Cengeloglu Y, Kocak I. Electrodialytic removal of fluoride from water: Effects of process parameters and accompanying anions. Sep Purif Technol 2008; 64: 14753.

http://dx.doi.org/10.1016/j.seppur.2008.09.009

[20] Lambert J, Avila-Rodriguez M, Durand G, Rakib M. Separation of sodium ions from trivalent chromium by electrodialysis using monovalent cation selective membranes. J Memb Sci 2006; 280: 219-25.

http://dx.doi.org/10.1016/j.memsci.2006.01.021

[21] Sadrzadeh M, Razmi A, Mohammadi T. Separation of different ions from wastewater at various operating conditions using electrodialysis. Sep Purif Technol 2007; 54: 147-56. http://dx.doi.org/10.1016/j.seppur.2006.08.023

[22] Ben Sik Ali M, Jellouli Ennigrou D, Hamrouni B. Iron removal from brackish water by electrodialysis. Environ Technol 2013 1-28.

[23] Ben Sik Ali M, Hamrouni B, Dhahbi M. Electrodialytic defluoridation of brackish water: effect of process parameters and water characteristics. CLEAN - Soil, Air, Water 2010; 38: 623-9.

[24] Puigdomenech I. Medusa Software. KTH Royal Institute of Technology, Department of Chemistry. Sweden; 2010 [cited 2010Dec06]: Available from: http://www.kth.se/en/che/ medusa/chemeq-1.369367 